\title{
Exploração vocacional em adolescentes: avaliação de uma intervenção em classe ${ }^{1}$
}

\author{
Martina Königstedt ${ }^{2}$ \\ Maria do Céu Taveira \\ Universidade do Minho, Braga, Portugal
}

\begin{abstract}
Resumo: Analisa-se o impacto de uma intervenção psicológica na exploração e tomada de decisão vocacional em adolescentes portugueses. Em contexto curricular e de classe, desenvolveram-se actividades de exploração do meio e do Eu com 39 alunos e 43 alunas do $9^{\circ}$ ano, entre 13 e 17 anos $(\mathrm{M}=14,4, \mathrm{DP}=0,95)$. Em um design pré/pós-teste, aplicaram-se o Career Exploration Survey (CES) e o Career Decision Difficulties Questionnaire (CDDQ). Os resultados do teste do sinal evidenciaram ganhos significativos $(\mathrm{p}<0,01)$ nas dimensões de exploração e diminuição significativa da falta de informação profissional $(\mathrm{p}<0,01) \mathrm{e}$ do total das dificuldades de decisão $(\mathrm{p}<0,05)$. Observou-se um padrão de correlações negativas (ró de Spearman) entre as duas medidas vocacionais, evidenciando uma relação entre a informação explorada na intervenção e a diminuição das dificuldades de decisão por falta de motivação. Em geral, os resultados suportam a importância do papel da exploração da carreira na diminuição das dificuldades de tomada de decisão.
\end{abstract}

Palavras-chave: orientação vocacional, adolescência, desenvolvimento.

\section{Adolescents career exploration: evaluation of an intervention}

\begin{abstract}
This study analyses the impact of a psychological intervention to promote vocational exploration and decisionmaking in Portuguese adolescents. Activities to foster exploration of self and environment were developed in a classroom program with 39 boys and 43 girls, all $9^{\text {th }}$ grade students, between 13 and 17 years of age $(\mathrm{M}=14,4, \mathrm{SD}=0.95)$. Following a pre/post-test design, the Career Exploration Survey (CES), and the Career Decision Difficulties Questionnaire (CDDQ) were administered. Results of sign-test showed significant increments $(\mathrm{p}<0.01)$ in all of the exploration dimensions, significant reduction of lack of occupational information $(\mathrm{p}<0.01)$ and of the total of career decision-making difficulties $(\mathrm{p}<0.05)$. Negative correlations (Spearman's rho) between the two career measures was observed, evidencing a relationship between information explored during intervention and decreased difficulty with decision-making due to lack of motivation. In general, results support the importance of career exploration on diminishing decision-making difficulties.
\end{abstract}

Keywords: career guidance, adolescence, development.

\section{Exploración vocacional en adolescentes: evaluación de una intervención en clase}

\begin{abstract}
Resumen: Evalúa-se el impacto de una intervención psicológica que fomenta la exploración y la decisión vocacional en adolescentes portugueses. Fueran efectuadas actividades de exploración del medio ambiente y del yo en contexto curricular de clase con 39 alumnos y 43 alumnas del curso $3^{\circ} \mathrm{ESO}, 13$ hasta 17 años (M=14,4, DP=0,95). Utilizó-se un diseño pre/posteste, con aplicación del Career Exploration Survey (CES) y Career Decision Difficulties Questionnaire (CDDQ). Resultados del test del señal evidencian beneficios significativos $(\mathrm{p}<0,01)$ en las dimensiones de la exploración, reducción significativa de ausencia de información ocupacional $(\mathrm{p}<0,01)$ y total de dificultades de decisión $(\mathrm{p}<0,05)$. Ha sido observado un patrón de correlaciones negativas (ró de Spearman) entre las dos medidas vocacionales, mostrando relación entre la información explorada e la disminución de las dificultades de decisión por falta de motivación. En general, resultados sostienen la importancia de la exploración de carrera en la disminución de las dificultades de decisión.
\end{abstract}

Palabras clave: orientación vocacional, adolescencia, desarrollo.

A avaliação da eficácia das intervenções é uma problemática estudada há mais de duas décadas na literatura vocacional (Brown e cols., 2003; Oliver \& Spokane, 1988; Whiston, Sexton, \& Lasoff, 1998). Em Portugal, apesar do aumento significativo de estudos com clientes reais da

\footnotetext{
${ }^{1}$ Este trabalho é derivado da Dissertação de Mestrado defendida pela primeira autora, no Programa de Pós-graduação em Psicologia Escolar, do Instituto de Educação e Psicologia, da Universidade do Minho. Este texto foi revisado segundo Acordo Ortográfico da Língua Portuguesa (1990), em vigor a partir de $1^{\circ}$ de janeiro de 2009 . Foram respeitadas as particularidades da Língua Portuguesa de Portugal.

${ }^{2}$ Endereço para correspondência:

Martina Königsted. Centro de Investigação em Psicologia. Departamento de Psicologia. Universidade do Minho. 4710-057. Braga, Portugal. E-mail: martinakonig@gmail.com
}

intervenção vocacional na última década (Silva, 2004), é escassa a investigação sobre a sua avaliação. Contribui para esta situação a reduzida investigação científica levada a cabo por profissionais de psicologia a trabalhar no terreno. Embora pese a falta de tempo evocada pelos psicólogos (Whiston, 1996), são de realçar a importância e os potenciais benefícios da ligação da prática psicológica aos resultados da investigação na Psicologia Vocacional. Segundo Whiston (1996), prática profissional e investigação podem ser entendidas como parte de um contínuo, no qual ambas constituem imperativos no exercício profissional do psicólogo.

Diversos autores da psicologia (Faria, 2008; Heppner \& Heppner, 2003; Whiston, Brecheisen, \& Stephens, 2003; Whiston \& Rahardja, 2008) têm estudado o processo e os resultados das intervenções vocacionais, em especial, do 
aconselhamento vocacional. Presentemente, uma das preocupações desta linha de estudo é determinar qual o tratamento mais eficaz para um dado tipo de população (Whiston e cols., 2003). Embora os resultados desta pesquisa não sejam ainda conclusivos (Spokane, 2004), constata-se que a consulta psicológica ocupa um lugar de destaque em meio escolar e constitui uma prática amplamente divulgada.

Apesar do seu mérito inquestionável, essa modalidade apresenta, contudo, algumas desvantagens. Por um lado, por inerência, a consulta psicológica desenrola-se numa base de participação voluntária. Embora este facto constitua uma vantagem, podendo favorecer a motivação dos clientes nas actividades, comporta o risco latente de excluir uma parte da população estudantil, porventura menos sensibilizada para a importância de equacionar a continuidade da sua formação, terminada a escolaridade obrigatória. Um segundo aspecto remete para a percepção errónea e frequente da comunidade escolar sobre a natureza acessória do desenvolvimento vocacional no processo educativo global do aluno. O carácter voluntário e extracurricular da consulta psicológica pode contribuir para acentuar a percepção do cunho transitório das suas actividades (Taveira, 2005).

As intervenções vocacionais, total ou parcialmente integradas ao currículo escolar, têm procurado ultrapassar tais dificuldades. Com efeito, a literatura ligada ao movimento da Educação para a Carreira sublinha o papel da escola na preparação para o trabalho e preconiza a aproximação entre estes dois mundos (Hoyt, 1995; Rodríguez-Moreno, 1995). Neste sentido, recomenda-se o desenho de intervenções psicológicas que promovam o desenvolvimento de conhecimentos, atitudes e competências de gestão e desenvolvimento da carreira ao longo da vida, como os programas de Educação para a Carreira, e que vão para além das intervenções mais pontuais, destinadas a ajudar as pessoas a decidir o que fazer da sua vida ocupacional num futuro próximo.

Embora seja difícil identificar uma única definição de Educação para a Carreira, existe acordo quanto ao facto de ser uma perspectiva que advoga a preparação da pessoa para a vida de trabalho como meta fundamental do sistema educativo (Diéguez \& González, 1995). De forma a poder atingir estes objectivos, a Educação para a Carreira visa a criar as condições para que cada pessoa possa adquirir um conjunto de competências essenciais como, por exemplo, competências académicas básicas e competências para tomar decisões de carreira e adquirir conhecimento acerca de si próprio(a) e das oportunidades educativas e ocupacionais (Herr \& Cramer, 1992).

Tem sido demonstrada a importância da prática de estratégias infusivas, versus aditivas ou mistas, de Educação para a Carreira numa perspectiva promocional e ao longo do percurso educativo do indivíduo (Arrington, 2000; Hoyt, 1995; Rodríguez-Moreno, 1995; Taveira, 2005). Neste contexto, os profissionais de psicologia utilizam, além do trabalho directo com os alunos, o aconselhamento parental e a consultoria psicológica como modalidades de eleição, envolvendo pais, professores, auxiliares de acção educativa, direcção da escola e demais agentes da comunidade na prossecução de objectivos de Educação para a Carreira.

A implementação de um projecto assim abrangente implica a satisfação de outras condições prévias, como o envolvimento e a formação dos professores (Gomes \& Taveira, 2001; Rodríguez-Moreno, 1995, 2008; Soares, 2002), o consentimento e participação activa do Órgão de Gestão Escolar, o envolvimento da comunidade educativa e a participação da família dos alunos (Hoyt, 1995). Diversos autores evidenciam a este propósito que a escolha vocacional dos jovens é influenciada pelas representações, quer positivas, quer negativas, das profissões desempenhadas pelos seus pais, e realçam a consequente importância do envolvimento destes no processo de tomada de decisão (Celen, Cok, Bosma, \& Djurre, 2006; Melo-Silva, Duarte, Santos, \& Bonfim, 2005; Whiston \& Keller, 2004).

Quanto aos conteúdos e objectivos específicos da Educação para a Carreira, autores como Arrington (2000), Law (2005) e Taveira (2005) frisam a importância de fomentar a exploração do self, do mundo do trabalho e do desempenho de papéis de vida, de forma a criar condições óptimas para a tomada de decisão vocacional realista. Jordaan (1963), um pioneiro no estudo da exploração vocacional, considera-a um motor do processo do desenvolvimento vocacional e pessoal do sujeito. A exploração vocacional permite o aumento do conhecimento acerca do Eu e do mundo, promove a construção de uma visão mais diferenciada da realidade e incrementa o grau de consciência do sujeito acerca das suas intenções e acções. Jordaan aponta ainda três consequências-chave da exploração vocacional: a autocompreensão, a compreensão do meio e a tomada de decisão.

Jordaan (1963) estabelece algumas relações relevantes entre a exploração vocacional e o autoconceito do sujeito. Este último inclui crenças conscientes do indivíduo acerca dos aspectos do self como também facetas desconhecidas. Estas crenças podem encontrar-se pouco ou muito ancoradas nas concepções do sujeito acerca de si próprio(a) e ter um carácter mais ou menos realista. Confrontada com novas experiências, a pessoa pode adquirir nova informação acerca de si que potencialmente será integrada ao seu autoconceito, contribuindo para uma melhor autocompreensão. Contudo, a investigação indica que são somente as crenças realistas e, simultaneamente, aquelas que o sujeito não percebe como sendo centrais na concepção do seu autoconceito que podem ser alteradas por meio da experiência (Jordaan, 1963). Fica, assim, patente a importância de fomentar a autocompreensão realista dos indivíduos, de forma a potenciar os efeitos benéficos da exploração.

Considerando o importante papel do processo da exploração na construção da identidade, autores como Blustein (1997) realizaram estudos no sentido de esclarecer as relações existentes entre os processos da formação da identidade e do desenvolvimento vocacional e realçam o papel crucial que assume a exploração do meio e do self no processo de 
formação da identidade do adolescente. A exploração vocacional constitui ainda um elemento essencial na tomada de decisão vocacional (Blustein, 1992) e relaciona-se com o aumento da capacidade do sujeito para tomar uma decisão.

Autores como Blustein (1992, 1997), Flum e Blustein (2000), Hughes e Karp (2004) e Taveira (1997) denotam que a exploração vocacional pode ser ainda encarada como uma competência mais ampla, um processo com funções adaptativas de grande importância ao longo da vida, já que pode favorecer a capacidade para lidar com as alterações nos contextos de vida.

Apesar da evidência existente acerca da importância da utilização de estratégias infusivas com início precoce, muitos países da Europa criaram os seus modelos próprios de Educação para a Carreira que incluem quer adaptações do modelo de infusão, quer a criação de seminários de apoio à tomada de decisão de carreira, a promoção de experiências de aprendizagem de trabalho ou até a construção de currículos de Educação para a Carreira (Herr, 2008).

Em Portugal, existem há mais de duas décadas programas estruturados de orientação de carreira e, desde a última década, programas de desenvolvimento vocacional inspirados na perspectiva da Educação para a Carreira. A maioria destes tem sido alvo de avaliação e resulta da colaboração entre investigadores e psicólogos a trabalhar no terreno (Araújo, Taveira, \& Lemos, 2004; Coelho, Correia, \& Taveira, 2004; Taveira, 2002; Pinto, 2002).

Em 2003 surgiu, na zona centro de Portugal, uma nova proposta de trabalho que consiste em utilizar no $9^{\circ}$ ano de escolaridade espaço e tempo de uma área curricular não disciplinar, a Área de Projecto, para promover a exploração e a decisão vocacional de jovens e, em alguns casos, apoiá-los no desenvolvimento de um projecto profissional. Importa referir que, em Portugal, o $9^{\circ}$ ano de escolaridade coincide com o final de escolaridade obrigatória, com a possibilidade de prosseguimento de estudos, sendo assim um ano no qual tradicionalmente se desenvolvem programas de orientação vocacional em meio escolar.

Contudo, esse novo modelo de organização da intervenção vocacional, inspirado na Educação para a Carreira, não tem sido alvo de avaliação. No sentido de colmatar esta lacuna, apresenta-se um estudo dos efeitos de um programa congénere para adolescentes, avaliando os resultados de uma intervenção vocacional em classe, em termos de exploração vocacional e dificuldades na tomada de decisão de carreira. Além disso, pretende-se estudar a interacção entre estas dimensões, antes e depois da intervenção.

\section{Método}

A intervenção foi realizada por uma psicóloga escolar, entre setembro de 2006 e janeiro de 2007, junto de todos os alunos do $9^{\circ}$ ano de escolaridade de uma escola pública da região centro de Portugal, no contexto da Área de Projecto, contando sempre com a colaboração do professor responsável. A Área de Projecto é de frequência obrigatória ao longo do $2^{\circ}$ e $3^{\circ}$ ciclos de escolaridade básica e visa a envolver os alunos na concepção, realização e avaliação de projectos, permitindo articular saberes de diversas áreas curriculares em torno de problemas ou tema de carácter transversal, recorrendo à metodologia de trabalho de projecto.

De forma a envolver os docentes no processo e promover a sua colaboração, o programa de intervenção foi-lhes, previamente, apresentado, realçando a filosofia, os objectivos gerais e as estratégias a utilizar. No período da intervenção, realizaram-se reuniões semanais entre o psicólogo e os docentes, a fim de aferir procedimentos e monitorizar o processo (Rodríguez-Moreno, 1995).

A metodologia utilizada na intervenção aproxima-se do trabalho de projecto cujos objectivos incluem: a) desenvolver a responsabilidade e o compromisso pessoal, b) melhorar as aptidões para o trabalho individual e em grupo, c) adquirir conhecimento aprofundado do tema estudado, d) desenvolver competências de comunicação e promover o desenvolvimento pessoal (Rodríguez-Moreno, 1995). Consideram-se condições importantes, para o desenvolvimento das actividades, a criação de um clima de respeito mútuo, o interesse pelos alunos e a valorização das suas opções (Ryan \& Deci, 2000), bem como a preocupação com um ambiente de aceitação, valorização e respeito por todas as profissões e a tentativa de combate dos estereótipos profissionais (Rodríguez-Moreno, 1995).

A intervenção consistiu em 12 sessões de 90 minutos cada, incluindo pré e pós-teste. $\mathrm{O}$ projecto principal baseiase na elaboração de um trabalho, individual ou em pequeno grupo, acerca de uma profissão ou área profissional, com a escolha da modalidade de concretização ao critério dos jovens. Inclui a apresentação do trabalho ao grande grupo, discussão e debate, de forma a possibilitar a partilha de informações, o confronto com expectativas criadas e o ensaio cognitivo de opções.

A fase inicial da intervenção compreende o estabelecimento da relação entre o psicólogo e os alunos da classe, a apresentação do racional das actividades a desenvolver, a explicitação dos objectivos e o estabelecimento da linha de base por meio do pré-teste. Segue-se um período de exploração de informação em contexto de sala (sessões dois-cinco), com o acesso a diversos meios, quer informáticos, quer em papel, apoiados pelo psicólogo e pelo professor da Área de Projecto. Nesta etapa da intervenção, pretende-se fomentar o desenvolvimento de uma atitude activa de procura de informação por parte dos jovens, fornecer informação sobre o sistema educativo português, promover a exploração e selecção de informação relevante e fomentar a avaliação das actividades realizadas e a estruturação da informação recolhida. Recorre-se à pesquisa apoiada, à apresentação multimédia do sistema educativo português, exploração detalhada de planos de estudo, elaboração de uma planificação do trabalho a realizar e ao apoio personalizado do psicólogo, por grupo de trabalho. Antes de iniciar a fase da apresentação, partilha e discussão dos trabalhos realizados (sessões sete-nove), 
promove-se a reflexão sobre rendimento escolar, preferências curriculares e extracurriculares e aspirações por meio de folhas de trabalho elaboradas para o efeito. $\mathrm{Na}$ parte final da intervenção (sessões dez e onze), explora-se informação breve sobre um leque variado de profissões e realiza-se um balanço individual e de grupo do projecto desenvolvido. Ambas as actividades são suportadas por materiais elaborados para o efeito.

Paralelamente, realizaram-se reuniões para dar a conhecer os objectivos da intervenção aos pais, sensibilizá-los para o seu papel na tomada de decisão dos filhos e informar acerca das opções educativas disponíveis após o $9^{\circ}$ ano escolar.

\section{Participantes}

Participou do estudo um total de 82 alunos do $9^{\circ}$ ano de escolaridade (39 alunos e 43 alunas), com idades entre os 13 e os 17 anos $(\mathrm{M}=14,40 ; \mathrm{DP}=0,97)$. O rendimento global do grupo, avaliado numa escala de 1 a 5 valores, é mediano $(\mathrm{N}=81 ; \mathrm{M}=3,01 ; \mathrm{DP}=0,46)$, e $49,4 \%$ dos alunos apresentam uma média de classificação final igual ou inferior a 2,91. Cerca de um quarto conta com uma (11\%) ou mais reprovações $(15,9 \%)$, ainda que $53,7 \%$ aspirem à frequência do Ensino Superior e 24,4\% pretendam estudar até ao $12^{\circ}$ ano. A análise dos dados sociodemográficos dos agregados familiares revela que a categoria socioprofissional mais representada é a de serviços e vendas, seguida de operários e artífices. Por seu turno, a habilitação escolar mais frequente é o $9^{\circ}$ ano. Contudo, em cerca de um quarto das famílias $(26,8 \%)$, pelo menos um dos pais concluiu 12 anos de escolaridade ou um curso do Ensino Superior, e um terço $(33,3 \%)$ da amostra provém de uma família onde a habilitação dos pais é o $6^{\circ}$ ano de escolaridade ou inferior. Se consideramos o nível de habilitação da família como possível indicador da estimulação sociocultural exercida sobre os jovens, estes dados reflectem a diversidade dos contextos familiares da amostra.

\section{Instrumentos}

O plano de investigação contempla a realização de um pré-teste (sessão 1) e de um pós-teste (sessão 12), compostos pelas mesmas medidas, o Career Exploration Survey (CES) (Stumpf, Colarelli, \& Hartman, 1983), adaptado à população portuguesa por Taveira (1997), e o Career Decision-Making Difficulties (CDDQ) (Gati, Krausz, \& Osipow, 1996a, 1996b), adaptado à população portuguesa por Silva (2005).

A versão portuguesa do CES é constituída por 54 itens que permitem avaliar cinco crenças, quatro comportamentos, e três reacções afectivas relacionadas com a exploração de carreira (Taveira, 1997). O estudo de análise factorial confirmatória realizado por Taveira (1997) permitiu evidenciar a robustez deste modelo de 12 dimensões consistentes de exploração vocacional para alunos e alunas do $9^{\circ}$ e $12^{\circ}$ anos.

A componente das crenças de exploração vocacional inclui cinco escalas: Estatuto de Emprego (EE, 3 itens) e
Certeza dos Resultados de Exploração (CR, 3 itens), Instrumentalidade Externa (IE, 11 itens), Instrumentalidade Interna (II, 4 itens) e Importância de Obter a Posição Preferida (IMP, 3 itens). A componente do Processo de Exploração comporta quatro escalas: a Quantidade de Informação (QI, 3 itens), a Exploração Intencional Sistemática (ESI, 2 itens), a Exploração do Meio (EM, 4 itens) e a Exploração de Si Próprio (ESP, 5 itens), Satisfação com a Informação (SI, 3 itens), Estresse com a Exploração (SE, 4 itens) e Estresse com a Decisão (SD, 4 itens) são as três escalas da componente das Reacções à Exploração. Os sujeitos respondem a cada item numa escala de resposta tipo Likert de cinco pontos, nas questões 1-43, e de sete pontos, nas questões 44-53 (em que 1 significa, por exemplo, "pouco", e 5 ou 7 significam "muito").

O CDDQ é composto originalmente por 44 itens (Gati e cols., 1996a, 1996b) e na versão portuguesa por 34 itens, ainda que a estrutura teórica da taxinomia das dificuldades de decisão se mantenha inalterada e com níveis satisfatórios de consistência interna (Silva, 2005). O CDDQ avalia três categorias principais de dificuldades: a Falta de Prontidão, a Falta de Informação e a Informação Inconsistente. Cada uma destas categorias divide-se em subcategorias de dificuldades, dez no seu conjunto. A categoria Falta de Prontidão situa-se antes do início do processo, enquanto as restantes referem dificuldades que podem surgir durante o processo de tomada de decisão. Todos os itens são respondidos numa escala tipo Likert com nove pontos, em que 1 significa "não me descreve", e 9 significa "descreve-me bem". É possível calcular médias para as subcategorias e categorias principais, bem como um valor total no questionário que corresponde à média das dez escalas. A Falta de Prontidão inclui três subcategorias de dificuldades: a) Falta de Motivação (FM, 3 itens), b) Indecisão Generalizada (IG, 3 itens) e c) Crenças Disfuncionais (CD, 4 itens). A categoria Falta de Informação divide-se em quatro dificuldades específicas e avalia, respectivamente, a falta de informação referente ao a) Processo de Tomada de Decisão (EPTD, 3 itens), ao b) Self (S, 4 itens), às c) Ocupações/ Profissões (OC, 3 itens) e às d) Fontes Adicionais de Informação (MIA, 2 itens). Finalmente, a categoria Dificuldades por Informação Inconsistente comporta as subcategorias a) Informação pouco Fidedigna (IPF, 3 itens), b) Conflitos Internos (CI, 5 itens) e c) Conflitos Externos (CE, 2 itens).

No que se refere às hipóteses de estudo, relativamente ao CES, prevê-se, no pós-teste, um aumento das médias registadas nas diversas escalas do questionário, com excepção das últimas duas que avaliam a quantidade de estresse indesejado, esperando-se uma diminuição dos valores respectivos. Relativamente ao CDDQ, espera-se uma diminuição das dificuldades na tomada de decisão após a intervenção, calculada pelas médias das diversas escalas, categorias e nota total no instrumento. Adicionalmente, prevê-se a existência de um padrão de correlações negativas entre as escalas do CES e as escalas e categorias do CDDQ, à excepção das escalas de estresse. 


\section{Considerações éticas}

Foram cumpridos os procedimentos éticos necessários, com a garantia da confidencialidade no tratamento e na análise dos resultados, e a obtenção do consentimento informado dos alunos para a investigação em causa.

\section{Procedimentos}

\section{Coleta de dados}

Os questionários foram administrados em classe, tendo sido controlada a ordem da sua apresentação. Antes da sua aplicação, foi definido o conceito de carreira - sequência de profissões e de outros papéis de vida que a pessoa desempenha desde a infância até à velhice, bem como a relação entre eles (Taveira, 2005).

\section{Análise dos dados}

A análise dos resultados incluiu testes de verificação da normalidade e da consistência interna (Alpha de Cronbach) das subescalas descritas, a partir dos resultados de pré-teste. Verificada a distribuição não normal dos dados para parte das escalas dos dois instrumentos, optou-se pela utilização de estatísticas não paramétricas. Foi decidido pelo uso do teste de sinal para a comparação das médias dos resultados do pré e pós-teste, apesar da sua menor potência quando comparado com o teste de Wilcoxon (Pestana \& Gageiro, 2003). Esta decisão foi tomada tendo em conta a violação do pressuposto teórico para a aplicação do último que exige a distribuição simétrica da diferença entre as escalas nas duas aplicações (Di=Yi-Xi). Foi ainda calculado o coeficiente de correlação ró de Spearman, para avaliar a correlação entre a exploração vocacional e as dificuldades na tomada de decisão de carreira

Procede-se à apresentação dos resultados da análise da normalidade e consistência interna dos dados recolhidos no pré-teste. Relativamente ao CES, verifica-se que todas as escalas, com excepção da Exploração do Meio e Importância da Posição Preferida, seguiram uma distribuição aproximadamente normal.

Relativamente ao CDDQ, regista-se um padrão semelhante de resultados, ainda que um número mais elevado de subescalas não obedeça à distribuição normal. Das dez subescalas que constituem o questionário, cinco apresentam uma distribuição aproximadamente normal - Indecisão Generalizada, Crenças Disfuncionais, Processo de Tomada de Decisão, Ocupações/Profissões, Fontes Adicionais de Informação, enquanto as restantes não seguem este padrão. Quanto às componentes principais e total CDDQ, somente a Falta de Informação apresenta uma distribuição normal.

No que se refere à consistência interna dos instrumentos na amostra, foi verificado que as escalas do CES apresentam valores bons ou aceitáveis ( $\alpha$ de Cronbach entre 0,93 e 0,69). Relativamente ao CDDQ, os valores são em média mais reduzidos, variando o $\alpha$ de Cronbach entre 0,81 e 0,56. As medidas foram consideradas válidas para o prosseguimento das análises.

\section{Resultados}

Na Tabela 1 apresentam-se os resultados do CES e do CDDQ, antes e após a intervenção. As quatro escalas de processo da exploração apresentam aumentos da média estatisticamente significativos ao nível de $\mathrm{p}<0,01$, no pós-teste, e relativamente às crenças de exploração, nenhuma das alterações é estatisticamente significativa. O mesmo acontece quanto à reacção de Satisfação com a Informação. No caso do Estresse com a Exploração e Estresse com a Decisão, verifica-se um aumento significativo dos valores de média, com nível de significância de $\mathrm{p}<0,05$, indicando que o estresse com a exploração e com a tomada de decisão aumentou significativamente após a intervenção (Tabela 1)

Tabela 1

Exploração Vocacional e Dificuldades na Decisão: Estatística do teste do sinal $(n=78)$

\begin{tabular}{|c|c|c|c|c|c|}
\hline $\begin{array}{c}\text { Variável } \\
\text { Dependente }\end{array}$ & pos $<$ pre & pos $>$ pre & pos $=$ pre & $\mathbf{Z}$ & Sig. \\
\hline $\mathrm{EE}$ & 24 & 38 & 16 & $-1,651$ & 0,099 \\
\hline CR & 28 & 31 & 19 & $-0,260$ & 0,795 \\
\hline IE & 33 & 42 & 3 & $-0,924$ & 0,356 \\
\hline II & 34 & 35 & 9 & 0,000 & 1,000 \\
\hline IMP & 30 & 31 & 17 & 0,000 & 1,000 \\
\hline QI & 14 & 58 & 6 & $-5,068$ & $0,000 * *$ \\
\hline ESI & 19 & 48 & 11 & $-3,421$ & $0,001 * *$ \\
\hline EM & 13 & 60 & 5 & $-5,384$ & $0,000 * *$ \\
\hline ESP & 23 & 46 & 9 & $-2,648$ & $0,008 * *$ \\
\hline SI & 24 & 36 & 18 & $-1,420$ & 0,156 \\
\hline SE & 26 & 48 & 4 & $-2,441$ & $0,015^{*}$ \\
\hline SD & 25 & 43 & 10 & $-2,062$ & $0,039 *$ \\
\hline PRONT & 45 & 31 & 2 & $-1,491$ & 0,135 \\
\hline FM & 30 & 33 & 15 & $-0,252$ & 0,801 \\
\hline IG & 45 & 28 & 5 & $-1,873$ & 0,061 \\
\hline $\mathrm{CD}$ & 38 & 31 & 9 & $-0,722$ & 0,470 \\
\hline F. INF. & 47 & 29 & 2 & $-1,950$ & 0,050 \\
\hline EPTD & 45 & 28 & 5 & $-1,873$ & 0,061 \\
\hline $\mathrm{S}$ & 43 & 30 & 5 & $-1,404$ & 0,160 \\
\hline $\mathrm{OC}$ & 48 & 22 & 8 & $-2,988$ & $0,003 * *$ \\
\hline MIA & 34 & 29 & 15 & $-0,504$ & 0,614 \\
\hline INF. INC. & 40 & 35 & 3 & $-0,462$ & 0,644 \\
\hline IPF & 35 & 37 & 6 & $-0,118$ & 0,906 \\
\hline CI & 33 & 41 & 4 & $-0,814$ & 0,416 \\
\hline $\mathrm{CE}$ & 29 & 37 & 12 & $-0,862$ & 0,389 \\
\hline Total & 49 & 27 & 2 & $-2,409$ & $0,015^{*}$ \\
\hline
\end{tabular}

Os valores de média observados para o CDDQ registram decréscimo estatisticamente significativo ao nível de 
$\mathrm{p}<0,01$, no pós-teste para a escala Ocupações/Profissões e, com nível de significância de $\mathrm{p}<0,05$, para o Total CDDQ. As variações registadas nas subcategorias de Indecisão Generalizada e Processo de Tomada de Decisão e na categoria Falta de Informação apresentam valores liminarmente significativos. Nas restantes escalas e categorias do CDDQ, não foi verificada uma alteração estatisticamente significativa dos valores de média, no pós-teste.

Como medida de correlação entre os dois instrumentos, foi calculado o coeficiente de correlação ró de Spearman entre todas as escalas do CES e categorias/subcategorias do CDDQ, tanto no pré-teste como no pós-teste. Nas Tabelas 2 e 3 , apresentam-se os resultados deste conjunto de análises.

Tabela 2

Pré-teste: Correlações entre dimensões da Exploração Vocacional e Dificuldades na Decisão $(n=80)$

\begin{tabular}{|c|c|c|c|c|c|c|c|c|c|c|c|c|}
\hline & $\mathbf{E E}$ & CR & IE & II & IMP & QI & ESI & EM & ESP & SI & SE & SD \\
\hline PRONT & .01 & -.08 & .17 & $.26^{*}$ & .13 & .01 & .02 & -.01 & .19 & -.08 & .07 & .17 \\
\hline F.M & -.20 & $-.33 * *$ & -.20 & -.07 & -.08 & -.16 & -.04 & -.20 & -.04 & -.17 & $.22 *$ & $.32 * *$ \\
\hline IG & .00 & -.02 & -.01 & .20 & .02 & -.15 & -.06 & -.04 & .18 & -.16 & .04 & .13 \\
\hline $\mathrm{CD}$ & .19 & .10 & $.47 * *$ & $.29 *$ & .21 & $.29 * *$ & .14 & $.22 *$ & .22 & .11 & -.09 & -.02 \\
\hline F. INF. & -.19 & $-.27 *$ & -.21 & .01 & -.06 & $-.53 * *$ & -.22 & $-.38 * *$ & -.04 & $-.48 * *$ & .15 & $.35 * *$ \\
\hline EPTD & -.03 & -.01 & -.14 & .10 & -.03 & $-.33 * *$ & .03 & -.18 & .06 & $-.23 *$ & .07 & .15 \\
\hline S & $-.24^{*}$ & $-.31 * *$ & -.13 & -.00 & -.08 & $-.37 * *$ & -.22 & $-.39 * *$ & -.09 & $-.38 * *$ & .15 & $.36 * *$ \\
\hline $\mathrm{OC}$ & $-.26^{*}$ & $-.30 * *$ & $-.36 * *$ & -.17 & -.18 & $-.55 * *$ & $-.26^{*}$ & $-.36^{* *}$ & -.12 & $-.50 * *$ & .13 & $.32 * *$ \\
\hline MIA & -.12 & $-.31 * *$ & -.13 & -.02 & .05 & $-.52 * *$ & $-.24 *$ & $-.32 * *$ & .08 & $-.36^{* *}$ & $.23 *$ & $.34 * *$ \\
\hline INF. INC. & -.21 & $-.29 *$ & $-.29 *$ & -.10 & -.16 & $-.29 * *$ & -.02 & $-.24 *$ & .01 & $-.28 *$ & .13 & $.42 * *$ \\
\hline IPF & -.14 & $-.26^{*}$ & $-.27 *$ & -.03 & -.13 & -.22 & -.14 & -.19 & .01 & $-.26^{*}$ & .13 & $.34 * *$ \\
\hline $\mathrm{CI}$ & $-.23^{*}$ & $-.31 * *$ & -.21 & -.16 & $-.24 *$ & $-.28 *$ & .04 & -.15 & .01 & $-.22 *$ & .10 & $.39 * *$ \\
\hline $\mathrm{CE}$ & -.15 & -.12 & -.15 & -.01 & -.10 & -.16 & .05 & -.14 & .05 & $-.23^{*}$ & $.27^{*}$ & $.27^{*}$ \\
\hline Total & -.15 & $-.29 * *$ & -.16 & .04 & -.08 & $-.38 * *$ & -.09 & $-.27 *$ & .07 & $-.37 * *$ & .17 & $.42 * *$ \\
\hline
\end{tabular}

* Correlação significativa ao nível 0,05 ** Correlação significativa ao nível 0,01

Tabela 3

Pós-teste: Correlações entre dimensões da Exploração Vocacional e Dificuldades na Decisão $(n=80)$

\begin{tabular}{|c|c|c|c|c|c|c|c|c|c|c|c|c|}
\hline & $\mathbf{E E}$ & CR & IE & II & IMP & QI & ESI & EM & ESP & SI & SE & SD \\
\hline PRONT & -.00 & -.00 & -.04 & .12 & $.28 *$ & -.19 & -.03 & -.01 & -.00 & $-.25 *$ & .16 & .13 \\
\hline F.M & -.19 & $-.34 * *$ & $-.29 *$ & $-.22 *$ & -.11 & -.21 & $-.29 * *$ & -.12 & $-.36 * *$ & $-.27 *$ & -.12 & .05 \\
\hline IG & -.06 & -.11 & -.11 & .10 & .12 & $-.25 *$ & -.14 & -.11 & -.03 & -.22 & $.29 * *$ & $.27^{*}$ \\
\hline $\mathrm{CD}$ & .18 & $.27^{*}$ & .21 & $.26^{*}$ & $.41 * *$ & .06 & $.26^{*}$ & $.23^{*}$ & $.23^{*}$ & -.03 & .18 & .06 \\
\hline F. INF. & $-.23^{*}$ & -.21 & $-.30 * *$ & -.11 & .03 & $-.47 * *$ & $-.27 *$ & $-.29 * *$ & -.21 & $-.38 * *$ & .16 & $.37 * *$ \\
\hline EPTD & -.14 & -.14 & -.21 & -.02 & .09 & $-.37 * *$ & $-.28 *$ & $-.24 *$ & -.18 & $-.31 * *$ & .19 & $.33 * *$ \\
\hline S & -.22 & -.14 & $-.30 * *$ & -.10 & .02 & $-.43 * *$ & $-.28 *$ & $-.28 *$ & -.20 & $-.34 * *$ & .09 & $.34 * *$ \\
\hline $\mathrm{OC}$ & $-.28 *$ & $-.27^{*}$ & $-.32 * *$ & -.14 & .00 & $-.44 * *$ & $-.23 *$ & $-.31 * *$ & -.21 & $-.40 * *$ & .09 & $.27 *$ \\
\hline MIA & -.15 & $-.22 *$ & $-.35 * *$ & -.21 & -.05 & $-.43 * *$ & $-.24 *$ & $-.25 *$ & $-.29 *$ & $-.37 * *$ & .13 & $.31 * *$ \\
\hline INF. INC & -.03 & -.16 & $-.33 * *$ & -.14 & .05 & $-.36 * *$ & $-.24 *$ & -.16 & -.20 & $-.35 * *$ & .07 & $.34 * *$ \\
\hline IPF & -.08 & -.15 & $-.34 * *$ & -.17 & -.05 & $-.33^{* *}$ & -.21 & $-.25^{*}$ & $-.23 *$ & $-.36^{* *}$ & .07 & $.27^{*}$ \\
\hline CI & -.03 & -.15 & $-.28 *$ & -.13 & -.08 & $-.26^{*}$ & $-.28 *$ & -.10 & -.17 & $-.29 * *$ & .01 & $.36^{* *}$ \\
\hline $\mathrm{CE}$ & .04 & -.14 & $-.32 * *$ & -.16 & .02 & $-.29 * *$ & -.12 & -.14 & $-.23^{*}$ & $-.43 * *$ & .22 & $.33 * *$ \\
\hline Total & -.12 & -.17 & $-.31 * *$ & -.09 & .02 & $-.42 * *$ & $-.23^{*}$ & -.22 & -.18 & $-.42 * *$ & .12 & $.34 * *$ \\
\hline
\end{tabular}

* Correlação significativa ao nível 0,05 ** Correlação significativa ao nível 0,01

Aleitura da Tabela 2 permite observar a existência de correlações significativas entre várias dimensões da exploração e dificuldades específicas na tomada de decisão vocacional, na situação de pré-teste. A Tabela 3 apresenta o padrão de correlações entre o CES e o CDDQ no momento do pósteste. São de registar as correlações negativas significativas 
entre a Exploração Sistemática Intencional, Exploração de Si Próprio, Certeza dos Resultados de Exploração, Instrumentalidade Externa, Instrumentalidade Interna, e Satisfação com a Informação do CES e a Falta de Motivação do CDDQ. Valores mais elevados nas primeiras associam-se a menores dificuldades na tomada de decisão de carreira por falta de motivação. Ao contrário do pré-teste, verifica-se uma correlação baixa e negativa entre a Quantidade de Informação e a Indecisão Generalizada, com o aumento de informação associado a menor dificuldade geral para tomar decisões. Existem, adicionalmente, associações de sentido positivo entre a Indecisão Generalizada e o Estresse com a Exploração e o Estresse com a Decisão. Inversamente, as correlações positivas, verificadas no pré-teste entre estas duas escalas do CES e a Falta de Motivação, deixam de se verificar após a intervenção. De referir que, tanto no pós como no pré-teste, várias dimensões da exploração associam-se a um aumento das dificuldades na tomada de decisão de carreira, sobretudo crenças desajustadas. No pós-teste, verifica-se um aumento de associações estatisticamente significativas entre o processo de exploração e as dimensões do CDDQ. Assim, a Exploração Sistemática Intencional passou a apresentar um maior número de correlações de sentido negativo com as escalas do CDDQ: após a intervenção, reforçou-se na amostra a relação entre Exploração Sistemática e Intencional e menores dificuldades na tomada de decisão por Falta de Informação e, em menor grau, por Informação Inconsistente. Assinala-se, ainda, o aumento das correlações negativas entre a Instrumentalidade Externa do CES e todas as dimensões da Falta de Informação e da Informação Inconsistente do CDDQ, menos o Processo de Tomada de Decisão onde a associação não chega a ser estatisticamente significativa.

Comparando pré-teste e pós-teste quanto ao padrão apresentado de correlações, constata-se um acréscimo das correlações negativas. Assim, aumenta o número de escalas do CDDQ a correlacionar-se negativamente com as dimensões Quantidade de Informação, Exploração Sistemática Intencional, Exploração de Si Próprio e Instrumentalidade Externa do CES. Reforçou-se o padrão existente entre a quantidade de informação, a exploração sistemática da informação, a reflexão acerca de si, a crença na utilidade da exploração do meio e menores dificuldades na tomada de decisão devidas à informação inconsistente. De registar também, no pós-teste, a correlação positiva entre o estresse antecipado com a decisão e as dificuldades na tomada de decisão devido à falta de informação acerca do processo de tomada de decisão.

\section{Discussão}

Os resultados do presente estudo evidenciam a importância de reflectir sobre o papel da intervenção em classe na promoção da exploração e decisão de carreira. Se por um lado se pode afirmar que esta intervenção parece estar associada à activação da exploração vocacional o que em si mesmo é um padrão de resultados muito favorável, o mesmo não se constata quando se consideram as crenças face à actividade exploratória ou às reacções à exploração. As crenças de exploração são, simultaneamente, um resultado da exploração efectuada e um factor da exploração futura (Taveira, 1997). Neste caso, parecem não ter sido intencionalmente afectadas como seria desejável. Assim, por meio das actividades de exploração do meio e do mundo profissional, os jovens poderão ter aumentado o seu realismo quanto às dificuldades actuais de obtenção do emprego desejado. Esta consciência pode estar na base da ausência de diferenças significativas no nível de Certeza dos Resultados da Exploração e no nível de Estatuto de Emprego percebido, registrados no grupo de participantes.

Ao mesmo tempo, no que respeita às reacções afectivas à exploração, verifica-se um aumento significativo do estresse com a exploração e face à decisão. Ou seja, os alunos ao longo do programa e, sobretudo na sua fase final, mais perto do momento de uma decisão de carreira, antecipam ou percepcionam mais ansiedade face à nova exploração ou à situação de decisão iminente. Esses resultados, apesar de contrariarem as hipóteses inicialmente definidas, corroboram outros dados da literatura da exploração vocacional sobre o possível aumento do estresse nos jovens, causado pelas actividades de exploração (Taveira, 1997). O facto de a intervenção em classe se ter realizado num ano em que uma decisão vocacional está iminente pode estar na origem do aumento registrado da ocorrência do comportamento exploratório (Blustein, 1997). Por outro lado, a intervenção pode ter potenciado o estresse sentido perante a urgência da decisão.

Reflectindo acerca do modelo de intervenção, este promove o envolvimento de todos os alunos do $9^{\circ}$ ano e aposta fortemente em actividades de exploração do meio e do self onde os jovens assumem um papel activo, enquanto o psicólogo e o professor adoptam uma postura de apoio e orientação.

A intervenção realizada promove a exploração de uma forma estruturada e apoiada, e as actividades fornecem aos jovens oportunidade para organizar a informação recolhida e delinear os seus planos. Esta opção parece ter efeitos positivos no que se refere à activação do comportamento exploratório dos jovens. Há indicadores que apontam que os alunos se envolveram na exploração e ficaram satisfeitos com a informação obtida. Como a ocorrência de exploração prediz o aparecimento de nova exploração vocacional e esta constitui uma base importante do avanço na tomada de decisão, os resultados obtidos neste estudo constituem um padrão de comportamento vocacional positivo.

A análise dos resultados relativos às dificuldades na tomada de decisão evidencia que, no pós-teste, a maioria das dimensões do CDDQ registra uma diminuição nos valores de média, à excepção da categoria principal Informação Inconsistente, onde se registra um aumento, embora ligeiro, dos valores das médias nas três subescalas. Contudo, como referido, somente duas dimensões do CDDQ apresentam uma diminuição da média com significância estatística 
- a subescala Ocupações/Profissões da categoria principal Falta de Informação e o Total do CDDQ. Assim, podemos afirmar que, no caso da amostra estudada, as actividades de exploração tiveram, em termos gerais, um efeito significativo na diminuição das dificuldades de tomada de decisão, contribuindo para a resolução de problemas associados à falta de informação ocupacional. Este resultado é consistente com os resultados obtidos no CES e evidencia a importância de apoiar, mais precocemente, a construção de conhecimento e o ensaio de competências relativas aos diferentes componentes de um processo de tomada de decisão vocacional, bem como a abordagem mais diferenciada das potenciais dificuldades dos jovens nesse âmbito (Silva, Paixão, \& Albuquerque, 2007).

Foi possível, ainda, verificar um padrão consistente de correlações negativas entre várias dimensões do CES e do CDDQ, indo ao encontro da segunda hipótese deste estudo. Com efeito, maior intencionalidade na exploração, maior exploração de si próprio, mais certeza dos resultados da exploração, mais reconhecimento da instrumentalidade interna e externa da exploração e maior satisfação com a informação obtida associam-se a menores dificuldades na tomada de decisão devido à falta de motivação para se envolver no processo. Por seu lado, a quantidade de informação profissional obtida pelos alunos nas actividades de exploração surge relacionada com menores dificuldades na decisão por falta de informação ou informação inconsistente sobre o mundo ocupacional, em especial, neste último caso, no pós-teste. Os resultados evidenciam ainda que a informação explorada no contexto da intervenção se relaciona com o aumento da prontidão para decidir e com a diminuição da indecisão generalizada e das dificuldades por informação inconsistente. Noutros casos, a relação positiva verificada, entre as dimensões das duas medidas, segue um padrão de correlação esperado.

Contrariamente ao esperado, as subescalas de Certeza dos Resultados de Exploração, Instrumentalidade Interna e Importância da Posição Preferida, bem como de Exploração Sistemática Intencional, Exploração do Meio, e Exploração de Si Próprio do CES apresentam correlações positivas com a subescala de Crenças Disfuncionais do CDDQ, no pós-teste. Ou seja, quanto mais elevada é a probabilidade de sucesso pessoal percebido para alcançar uma posição no mercado de emprego desejado, quanto mais se acredita no valor instrumental da exploração de si próprio e do meio ocupacional, quanto maior é a importância atribuída aos objectivos vocacionais e mais intencionalmente se explora e se adquire informação sobre si próprio e sobre as oportunidades ocupacionais, maior a probabilidade de evidenciar uma percepção distorcida, acerca do processo de tomada de decisão, e expectativas irracionais ou pensamentos disfuncionais face à carreira. Este resultado é inesperado e parece preocupante para a prática da intervenção vocacional, evidenciando uma matriz de fraco desenvolvimento vocacional dos alunos estudados, bem como a necessidade de maior focagem nas dimensões sociocognitivas da tomada de decisão. Trata-se de uma padrão de resultados que remete uma vez mais os investigadores e profissionais para a necessidade de trabalhar, de forma explícita, as crenças e conhecimentos dos jovens acerca dos processos vocacionais, no contexto da intervenção especializada.

\section{Considerações finais}

Apesar de os resultados globais do estudo suportarem a ideia de ganhos com a intervenção em classe e o papel da promoção da exploração deliberada da carreira na tomada de decisão, várias limitações inerentes à presente investigação sugerem algumas cautelas na interpretação dos resultados e a necessidade de desenvolvimento deste tipo de pesquisa. Assim, o uso de uma amostra de conveniência de clientes reais da intervenção vocacional bem como a utilização de um desenho metodológico de grupo único com pré-teste e pós-teste impedem o controlo das variáveis de selecção. Apesar do design utilizado nos fornecer informação importante sobre o estado inicial dos sujeitos a nível da exploração e dificuldades na tomada de decisão, não oferece garantias de controlo de fontes que possam estar a afectar a validade interna dos resultados. Será importante, em futuros estudos, garantir maior aleatoriedade da amostra e uma segunda condição, um grupo de controlo com as mesmas características vivenciais do grupo experimental. Outro aspecto prende-se às actividades desenvolvidas com os pais dos jovens e cujos resultados deveriam ter sido também avaliados. Está patente a necessidade de colmatar esta falha em investigações posteriores, para além de se considerar igualmente importante estender e aperfeiçoar a componente da intervenção com os pais e encarregados de educação e de avaliar outras dimensões, como a sua satisfação com os resultados e o processo da intervenção.

A política da Educação para a Carreira no sistema de ensino não designa um programa, mas sim uma perspectiva educativa e, se quisermos, desenvolvimentista da carreira. Recorre a um conjunto de estratégias diversificadas como actividades de coordenação, gestão e consultoria, à realização de seminários, a experiências laborais breves, a actividades de informação, consulta psicológica, entre outras. Estas intervenções têm sido desenvolvidas com o apoio dos estabelecimentos escolares e veiculam algumas características da Educação para a Carreira, mas não o são verdadeiramente, embora pudessem fazer parte de uma estratégia para a carreira, já que são eficazes. Nesta perspectiva, a nossa intervenção será mais propriamente uma intervenção vocacional em classe que já tem um cariz mais preventivo e se inspira na Educação para a Carreira.

\section{Referências}

Araújo, A., Taveira, M. C., \& Lemos, M.S. (2004). Uma experiência de intervenção precoce no desenvolvimento vocacional em contexto pré-escolar. In M. C. Taveira., H. Coelho, H. Oliveira, \& J. Leonardo (Orgs.), Desenvolvimento vocacional ao longo da vida: Fundamentos, princípios e orientações (pp. 197-209). Coimbra: Livraria Almedina. 
Arrington, K. (2000). Middle grades career planning programs. Journal of Career Development, 27, 103-109.

Blustein, D. L. (1992). Applying current theory and research in career exploration to practice. Career Development Quarterly, 41, 174-184.

Blustein, D. L. (1997). A context-rich perspective of career exploration across the life roles. Career Development Quarterly, 45, 260- 274.

Brown, S. D., Ryan Krane, N. E., Brecheisen, J., Castelino, P., Budisin, I., Miller, M., \& Edens, L. (2003). Critical ingredients of career choice intervention: More analyses and new hypotheses. Journal of Vocational Behavior, 62, 411-428.

Celen, N., Cok, F., Bosma, H. A., \& Djurre, H. Z. (2006). A percepção de adolescentes e de pais sobre decisão e autonomia. Paidéia (Ribeirão Preto), 16, 349-363.

Coelho, H., Correia, L., \& Taveira, M. C. (2004). Programas de desenvolvimento vocacional na Casa Pia de Lisboa. In M. C. Taveira, H. Coelho, H. Oliveira, \& J. Leonardo (Coords.), Desenvolvimento vocacional ao longo da vida: Fundamentos, princípios e orientações (pp. 260267). Coimbra: Livraria Almedina.

Diéguez, A. R., \& González, M. P. (1995). La educación para la carrera. Delimitación conceptual. In M. L. Rodríguez (Coord.), Educación para la carrera y diseño curricular: Teoría y práctica de programas de educación para el trabajo (pp.79-122). Barcelona: U. B.

Faria, L. C. F. (2008). A Eficácia da consulta psicológica vocacional de jovens: Estudo do impacto de uma intervenção. Dissertação de doutorado não publicada, Universidade do Minho, Braga.

Flum, H., \& Blustein, D.L. (2000). Reinvigorating the study of vocational exploration: A framework for research. Journal of Vocational Behavior, 56, 380-404.

Gati, I., Krausz, M., \& Osipow, S.H. (1996a). A taxonomy of career decision-making difficulties. Recuperado em 10 agosto 2007, de http//go.to.cddq

Gati, I., Krausz, M., \& Osipow, S. H. (1996b). A taxonomy of difficulties in career decision making. Journal of Counseling Psychology, 43, 510-526.

Gomes, I. T., \& Taveira, M. C. (2001). Educação para a carreira e formação de professores. Braga: Universidade do Minho.

Heppner, M. J., \& Heppner, P. P. (2003). Identifying process variables in career counseling: A research agenda. Journal of Vocational Behavior, 62, 429-452.

Herr, E. L. (2008). Abordagens às intervenções de carreira: Perspectiva histórica. In M. C. Taveira \& J. T. Silva (Coords.), Psicologia vocacional: Perspectivas para $a$ intervenção (pp.13-27). Coimbra: Imprensa da Universidade de Coimbra.

Herr, E. L., \& Cramer, S. H. (1992). Career guidance and counseling through the life span: Systematic approaches (4th ed.). New York: Harper Collins Publishers.
Hoyt, K. B. (1995). El concepto de educación para la carrera y sus perspectivas. In M. L. Rodríguez (Coord.), Educación para la carrera y diseño curricular: Teoría y práctica de programas de educación para el trabajo (pp.15-37). Barcelona: U. B.

Hughes, K. L., \& Karp, M. M. (2004). School-based career development: A synthesis of the literature. Columbia: Institute on Education and the Economy Teachers College.

Jordaan, J. P. (1963). Exploratory behavior: The formation of self and occupational concepts. In D. E. Super, R. Starisshevsky, R. Matlin, \& J. P. Jordaan (Eds.), Career development: Self-concept theory (pp. 42-78). New York: College Entrance Board.

Law, B. (2005). Liberté, futilité...autonomé-careers education as an emancipatory activity. In B. Irving, \& B. Malik (Eds.), Critical reflections in guidance. London: Routledge-Falmer.

Melo-Silva, L. L., Duarte, C. V., Santos, M. A., \& Bonfim, T. A. (2005). A influência familiar na escolha profissional dos filhos, na perspectiva de mães de clientes em processo de orientação profissional. In C. P. Simon, L. L. MeloSilva, \& M. A. Santos (Orgs.), Formação em psicologia: Desafios da diversidade na pesquisa e na prática (pp. 261- 282). São Paulo: Vetor.

Oliver, L. W., \& Spokane, A. R. (1988). Career-intervention outcome: What contributes to client gain. Journal of Counseling Psychology, 35, 447-462.

Pestana, M. H., \& Gageiro, J. N. (2003). Análise de dados para ciências sociais: A complementaridade do SPSS (3a ed.). Lisboa: Edições Sílabo.

Pinto, H. R. (2002). Programas construir o futuro: Manual Técnico. Santarém: JHM Edições.

Rodríguez Moreno, M. L. (1995). Aplicaciones de la educación para la carrera al contexto de la reforma de las enseñanzas. In M. L. Rodríguez (Coord.), Educación para la carrera y diseño curricular: Teoría y práctica de programas de educación para el trabajo (pp. 123-221). Barcelona: U. B.

Rodríguez Moreno, M. L. (2008). A educação para a carreira: Aplicações à infância e à adolescência. In M. C. Taveira \& J. T. Silva (Coords.), Psicologia vocacional: Perspectivas para a intervenção (pp. 29-58). Coimbra: Imprensa da Universidade de Coimbra.

Ryan, R. M., \& Deci, E. L. (2000). Intrinsic and extrinsic motivations: Classic definitions and new directions. Contemporary Educational Psychology, 25, 54-67.

Silva, J. M. T. (2004). A eficácia da intervenção vocacional em análise: Implicações para a prática psicológica. In M. C. Taveira, H. Coelho, H. Oliveira, \& J. Leonardo (Coords.), Desenvolvimento vocacional ao longo da vida: Fundamentos, princípios e orientações (pp. 95124). Coimbra: Almedina. 
Silva, J. T. (2005). Versão adaptada do Career DecisionDifficulties Making Questionnaire (Policopiado). Coimbra: FPCE.

Silva, J. T., Paixão, M. P., \& Albuquerque, M. (2007). Relationship between locus of control, causal attributions, and career decision making self-efficacy with career decision difficulties. Poster apresentado no 10 European Congress of Psychology, Praga.

Soares, A. B. A. (2002). Educação para a carreira ao nível do ensino básico: Estratégias para a formação de professores. Tese de mestrado não publicada, Universidade do Minho, Braga.

Spokane, A. R. (2004). Avaliação das intervenções de carreira. In L. M. Leitão (Ed.), Avaliação psicológica em orientação escolar e profissional (pp. 455-473). Coimbra: Quarteto.

Stumpf, S. A., Colarelli, M. S., \& Hartman, K. (1983). Development of the career exploration survey (CES). Journal of Vocational Behavior, 22, 191-226.

Taveira, M. C. (1997). Exploração e desenvolvimento vocacional de jovens: Estudo sobre as relações entre a exploração, a identidade e a indecisão vocacional. Tese de doutorado não publicada, Instituto de Educação e Psicologia. Braga: Universidade do Minho.

Taveira, M. C. (2002). Educação e desenvolvimento de carreira ao longo da vida: A intervenção vocacional baseada em programas. In M. C. Taveira (Org.), Homenagem ao professor Doutor J. Ferreira Marques. Sacavém: Stória Editores.

Taveira, M. C. (2005). Comportamento e desenvolvimento vocacional na adolescência. In M. C. Taveira (Coord.), Psicologia escolar: Uma proposta científico-pedagógica (pp. 143-177). Coimbra: Quarteto.

Whiston, S. C. (1996). Accountability through action research: Research methods for practitioners. Journal of Counseling \& Development, 74, 616-623.

Whiston, S. C., Brecheisen, B. K., \& Stephens, J. (2003). Does treatment modality affect career counseling effectiveness? Journal of Vocational Behavior, 62, 390410.

Whiston, S. C., \& Keller, B. K. (2004). Expanding research concerning family influences on career development: Cultivating a number of brown spots. The Counseling Psychologist, 32, 612-617.

Whiston, S. C., \& Rahardja, D. (2008). Vocational counseling process and outcome. In S. D. Brown \& R. W. Lent (Eds.), Handbook of counseling psychology (4th ed., pp. 444-461). New Jersey: John Wiley \& Sons.

Whiston, S. C., Sexton, T. L., \& Lasoff, D. L. (1998). Career intervention outcome: A replication and extension. Journal of Counseling Psychology, 45, 150 -165.
Martina Königstedt é doutoranda em Psicologia Vocacional pelo Programa de Doutoramento em Psicologia da Escola de Psicologia da Universidade do Minho, Portugal.

Maria do Céu Taveira é Professora Adjunta da Escola de Psicologia da Universidade do Minho, campus de Gualtar, Braga, Portugal.

Recebido: 27/01/2009

$1^{a}$ revisão: 29/05/2009

$2^{a}$ revisão: $26 / 08 / 2009$

Aceite final: 03/09/2009 